\title{
Efeitos da Condição Sorológica Sobre as Escolhas Reprodutivas de Mulheres HIV Positivas
}

\author{
Effects of Seropositivity in Reproductive Choices of Women \\ Living With HIV/Aids
}

\author{
Ana Carolina Cunha Sant'Anna ${ }^{*}, a, b$ \& Eliane Maria Fleury Seidl ${ }^{c}$ \\ ${ }^{a}$ Universidade Regional da Bahia, ${ }^{b}$ Faculdade Santíssimo Sacramento \\ ${ }^{\circ}$ Universidade de Brasília
}

\begin{abstract}
Resumo
O estudo investigou a percepção de mulheres vivendo com HIV/Aids quanto aos efeitos da soropositividade sobre suas escolhas reprodutivas. Optou-se pelo delineamento qualitativo com uso de entrevista individual semi-estruturada com trinta mulheres HIV positivas em idade reprodutiva. A maior parte delas $(n=18)$ afirmou que a soropositividade modificou o desejo de ter filhos. As categorias de motivos mais freqüentes foram o receio do risco de transmissão do HIV para o bebê e soropositividade como sinônimo de morte. Os resultados sinalizam a necessidade de que os serviços atuem em consonância com os programas de atenção integral à saúde da mulher e os princípios do Sistema Único de Saúde, acolhendo e respeitando as decisões reprodutivas de mulheres soropositivas.

Palavras-chave: Escolhas reprodutivas; Mulheres vivendo com HIV/Aids; Direitos reprodutivos; Transmissão vertical do HIV.

Abstract

AIDS epidemiological profile indicates a feminine trend particularly among those in the reproductive age. The study investigated the HIV positive women perception of the seropositivity effects on their reproductive choices. It was chosen a qualitative research design with the use of semi-structured individual interviews with thirty HIV positive women in their reproductive age. As the most frequent categories of reasons, most women reported they did not wish to have children, showing the fear of HIV transmission to the baby and seropositivity as a synonym of death. The findings indicate the need for the services in HIV/AIDS to act in line with the programs of comprehensive health care of women and the principles of Brazilian Health System, respecting the reproductive decisions of seropositive women.

Keywords: Reproductive choices; Women living with HIV/Aids; Reproductive rights; Mother-to-child HIV transmission
\end{abstract}

Desde a descoberta do HIV/Aids, na década de 80, houve um acúmulo de conhecimentos científicos que nortearam as políticas públicas em todo o mundo (Lopes, 2003). No Brasil, como resultado de profundas desigualdades econômicas e sociais, a propagação da infecção pelo HIV vem sofrendo diversas transformações em seu perfil, sinalizando um processo de feminização da epidemia, particularmente entre as mulheres mais pobres e em idade reprodutiva (Simões-Barbosa, 2001). Assim, dos 13.249 casos do sexo feminino notificados em 2006, 81,1\% tinham entre 20 e 49 anos (Ministério da Saúde, 2007).

Tais dados apontam para a necessidade de um redirecionamento das políticas públicas na medida em que este novo panorama tem desnudado a condição da vulnerabilidade feminina frente ao HIV (Guilhem, 2005). O crescimento da infecção entre as mulheres traz implicações em

*Endereço para correspondência: Universidade Regional da Bahia, Av. Tamburugy, 474, Patamares, Salvador, BA, Brasil, CEP 40000-000. E-mail: anac.santanna@gmail.com diferentes esferas de suas experiências, tais como a decisão sobre ter ou não filhos após o diagnóstico de soropositividade para o HIV. A maternidade, que em nossa cultura parece ser parte de um papel social esperado, pode tornarse ameaçada pela condição de soropositividade (Knauth, 1999).

Denomina-se transmissão vertical a infecção da criança pelo vírus HIV durante a gestação, parto ou amamentação (Ministério da Saúde, 2006). Resultados obtidos com o protocolo ACTG 076 - nome pelo qual ficou conhecido o estudo do Aids Clinical Trial Group - possibilitaram uma redução significativa do risco de transmissão vertical do HIV. À guisa de exemplo, foi realizada uma análise comparativa entre dois grupos de gestantes assintomáticas: o primeiro fez uso do anti-retroviral zidovudina (AZT) e o segundo grupo utilizou placebo. Os resultados apontaram para uma redução na transmissão vertical do HIV no grupo que utilizou o AZT quando comparado ao grupo controle (Connor et al., 1994). Este e outros estudos que se sucederam motivaram a implementação de ações de 
profilaxia da transmissão vertical pelo governo brasileiro, resultando na Lei Federal 9.313/96 que garante a disponibilização gratuita e universal do protocolo de profilaxia da transmissão vertical, que reduziu o risco transmissão de aproximadamente $30 \%$ para menos de $1 \%$ (Ministério da Saúde, 2006).

$\mathrm{O}$ efeito da condição de soropositividade sobre a vida sexual e afetiva da mulher tem sido investigado por alguns autores. Paiva, Latorre, Gravato e Lacerda (2002) verificaram que, apesar de a maior parte (54\%) das 1.068 entrevistadas relatar vida amorosa e sexual ativas, a comunicação do diagnóstico ao parceiro, a negociação do uso de preservativos e o medo de rejeição foram comumente citados como eventos estressores. Santos et al. (2002), por sua vez, observaram que, em um grupo de 148 mulheres soropositivas, menos da metade continuou mantendo vida sexual ativa, embora tenham relatado desejo de fazer sexo.

O exercício da sexualidade para as mulheres em nossa cultura parece ainda estar atrelado à maternidade. Apesar de grande parte dos estudos referir-se ao impacto negativo da soropositividade na vida sexual das mulheres, isto parece não ter ocorrido com relação ao desejo de ter filhos. Pesquisa de Paiva et al. (2002) verificou que, dentre aquelas que tinham parceria sexual estável, $13 \%$ relataram que desejavam ter filhos, sendo que essa proporção foi maior entre o grupo de mulheres com menos de 30 anos (39\%). Resultados de Santos et al. (2002) foram na mesma direção: em amostra de 148 mulheres, $21 \%$ manifestaram o desejo de ser mãe.

$\mathrm{Na}$ tentativa de compreender como o HIV influenciaria as escolhas reprodutivas de mulheres antes do protocolo ACTG 076, estudo desenvolvido com população de baixa renda no sul do Brasil analisou associações entre maternidade e relações familiares. Os resultados mostraram que as decisões das mulheres em levar adiante ou não uma gravidez estiveram relacionadas ao tipo de aliança conjugal existente. Relatos indicaram ainda que, para as que engra-vidaram sabendo-se portadoras do vírus ou mesmo já sintomáticas, um filho significaria algo que as motivaria a viver (Knauth, 1997). Corroborando os achados de Knauth (1997), uma pesquisa enfocou as representações das mulheres HIV positivas, sendo que a maioria das entrevistadas referiu-se ao desejo de ter filhos e à expectativa de continuidade de suas vidas. Entre as que ainda não tinham filhos, o desejo de ser mãe parece ter sido interditado pela condição sorológica (Cabral, 1998).

O protocolo de prevenção da transmissão vertical do HIV estabelece a indicação de não-amamentação dos bebês expostos ao vírus. No entanto, o ato de amamentar tem povoado o universo feminino como um símbolo representativo da maternidade (Moreno, Rea, \& Ventura-Filipe, 2006). Em investigação realizada por Sant'Anna, Seidl e Galinkin (2008), mulheres soropositivas que participaram de um grupo focal pontuaram que o fato de não amamentar poderia, por um lado, denunciar a condição sorológica da mulher e, por outro, representar o não cumprimento de um papel social esperado.

Outro tema de interesse se refere às ações contraceptivas adotadas pelas mulheres soropositivas. Galvão, Cerqueira e Marcondes-Machado (2004) investigaram o uso de medidas contraceptivas entre mulheres com HIV/Aids, sendo que as casadas constituíram o maior grupo (60,3\%). A maior parte delas $(79,5 \%)$ informou utilizar medidas adequadas de anticoncepção (uso consistente de preservativo masculino ou feminino e abstinência sexual), enquanto que entre as não casadas também houve maior frequiência de adoção de medidas adequadas $(96,6 \%)$. A freqüência de uso de estratégias inadequadas de proteção (uso irregular de preservativo, associado ou não a contraceptivo oral e coito interrompido) chegou a $20 \%$ entre as casadas e a $3,4 \%$ entre as não casadas. É digno de nota que a prática de abstinência sexual foi apontada como medida contraceptiva por $28,8 \%$ das mulheres, sendo que os motivos para esta escolha estariam relacionados ao medo de contaminar o parceiro e o bebê.

Ao compararem grupos de mulheres soropositivas e soronegativas quanto às escolhas reprodutivas, Bedimo, Bessinger e Kissinger (1998) verificaram que mulheres HIV positivas tiveram quedas nas taxas de fertilidade e elevação nas taxas de esterilização, quando comparadas às soronegativas. Estudo brasileiro corroborou esses achados, ao observar que as taxas de esterilização em mulheres soropositivas eram maiores em relação à população feminina em geral (Barbosa \& Knauth, 2003).

A mudança do panorama epidemiológico aponta para a consolidação da Aids como enfermidade crônica, que tem refletido no aumento da conjugalidade entre pessoas com sorologias diferentes para o HIV. De acordo com Polejack (2001), para o casal sorodiferente a decisão de ter ou não filhos apresenta peculiaridades, como a possibilidade de transmissão do HIV para o parceiro não infectado, além da transmissão da mãe para o bebê. Como sinalizam Polejack e Costa (2002), a partir do diagnóstico de soropositividade os casais precisam desenvolver estratégias de enfrentamento em relação ao risco sexual visando diminuir o estresse oriundo da preocupação com uma possível infecção do parceiro/a, ao lado do desejo de permanecerem sexualmente ativos e realizarem suas escolhas reprodutivas.

Reis (2004) descreveu e analisou o impacto da sorodiferença na vida afetivo-sexual de pessoas portadoras do HIV que conviviam com parceiro/a heterossexual soronegativo/a. Entre as onze pessoas participantes do estudo, observou-se diminuição do desejo sexual aliado à desconfiança sobre a eficácia do preservativo na prevenção da infecção pelo HIV. Relatos referentes a dificuldades de diálogo sobre o tema entre os casais pareciam interferir em suas escolhas reprodutivas. Ainda no panorama das decisões reprodutivas entre casais sorodiferentes, Dalapria e Neto (2004) verificaram a redução das práticas sexuais e dificuldades de negociação do uso consistente do preservativo. Ademais, dentre os seis casais estudados, nenhum declarou conhecer técnicas de reprodução assistida, que poderiam ser indicadas nesses casos.

Diante da complexidade da temática referente à sexualidade e reprodução no contexto da soropositividade, o presente estudo investigou a percepção de mulheres HIV positivas quanto aos efeitos da condição sorológica sobre suas escolhas reprodutivas. Esta pesquisa se justifica na 
medida em que fornece elementos relevantes ao campo dos direitos sexuais e reprodutivos e pode contribuir para o aprimoramento das políticas públicas nas áreas da saúde da mulher e do HIV/Aids.

\section{Método}

Trata-se de um estudo descritivo, de delineamento qualitativo e de corte transversal, que utilizou entrevista individual semi-estruturada como técnica de coleta de dados.

\section{Local}

No intuito de obter uma maior abrangência entre as mulheres pesquisadas, optou-se por uma diversificação dos locais em que foram realizados os convites, sendo dois serviços públicos de saúde e uma Organização Não Governamental (ONG). Dentre os serviços públicos, foram selecionados o Hospital Universitário de Brasília (HUB) e a Unidade Mista da Regional Sul de Saúde, por serem referência no atendimento em HIV/Aids no Distrito Federal (DF). Além dos dois serviços, foram entrevistadas mulheres da Associação Brasiliense de Combate à Aids - Grupo Arco Íris, ONG que atua na área do HIV/Aids no DF.

\section{Participantes}

Participaram do estudo trinta mulheres soropositivas, que constituíram uma amostra de conveniência. A idade das participantes variou entre 18 e 44 anos $(M=33,2 D P=6,67)$. Quanto ao nível de escolaridade, quinze participantes haviam cursado até o ensino médio completo e quatorze haviam cursado até o ensino fundamental. Mais da metade delas $(n=20)$ estava convivendo com parceiro e o tempo de relacionamento variou de oito meses a quatorze anos. Vinte e uma participantes tinham filhos, sendo que dezesseis delas tinham entre um e três filhos. Com relação à cor da pele, treze participantes se auto-referiram negras, dez se consideraram pardas e sete brancas.

A composição da amostra pesquisada se deu de forma consecutiva e intencional, até completar o número estimado previamente, de acordo com os objetivos do estudo e o delineamento metodológico. Estariam aptas a participar mulheres em idade reprodutiva (entre 18 e 45 anos), que não estivessem internadas ou não tivessem tempo de diagnóstico positivo para o HIV inferior a seis meses, pois o impacto psicológico da internação e/ou da descoberta recente poderiam influenciar negativamente as respostas das participantes. Três mulheres se recusaram a participar do estudo.

\section{Instrumento}

Foi utilizado roteiro de entrevista semi-estruturado, com dez questões abertas. Em sua elaboração, foram considerados os resultados de um estudo piloto que pesquisou um grupo focal com mulheres atendidas em serviços de saúde do DF, quando foi trabalhado o tema escolhas reprodutivas em HIV/Aids (Sant'Anna et al., 2008). Um levantamento de tópicos relacionados ao objeto de estudo, a partir da literatura disponível indexada em bases de dados nacio- nais e internacionais, também forneceu subsídios para a confecção do roteiro.

A entrevista abordou questões referentes ao desejo de ter filhos, revelação do diagnóstico de soropositividade, práticas contraceptivas e efeitos da condição sorológica sobre as escolhas reprodutivas. Informações sociodemográficas e médico-clínicas também foram investigadas, constituindo uma parte mais estruturada do instrumento.

\section{Aspectos Éticos e Procedimentos de Coleta}

$\mathrm{O}$ projeto de pesquisa foi submetido à apreciação dos Comitês de Ética em Pesquisa da Faculdade de Ciências da Saúde da Universidade de Brasília e da Secretaria de Estado de Saúde do Distrito Federal, sendo aprovado por ambos conforme processos números 009/2006 e 738/2006, respectivamente. De acordo com os preceitos éticos que regem as pesquisas com seres humanos, foi elaborado um Termo de Consentimento Livre e Esclarecido, reiterando os objetivos do estudo, duração estimada da entrevista e convidando-as a participar. $\mathrm{O}$ sigilo quanto às informações fornecidas, bem como a voluntariedade da participação, foram explicitados. A gravação em áudio dos relatos foi efetuada após autorização das participantes.

As entrevistas foram realizadas entre abril e dezembro de 2006 pela pesquisadora principal. Nos serviços de saúde, o convite às participantes foi feito nas salas de espera em dias de atendimento médico ou psicossocial. Nos dois locais foram disponibilizadas salas que garantiram privacidade e conforto para a realização das entrevistas. Na ONG, os convites foram realizados nos grupos de ajuda mútua pela pesquisadora. Todas as entrevistas foram realizadas individualmente e o tempo médio de realização foi de quarenta minutos.

\section{Análise de Dados}

Por se tratar de uma abordagem qualitativa, os dados colhidos foram interpretados a partir dos relatos das participantes, por meio de análise de conteúdo (Bardin, 1977/ 1979). As entrevistas foram transcritas na íntegra. Após uma leitura flutuante do córpus de análise, os relatos verbais foram analisados e categorizados a partir de seu conteúdo, por dois pesquisadores de modo independente, visando concordância igual ou superior a $70 \%$ para a identificação, nomeação e freqüência das categorias. Procedeu-se ainda à seleção de trechos de relatos das mulheres participantes como exemplos das categorias.

A caracterização sociodemográfica e médico-clínica das participantes foi analisada com o uso do software Statistical Package for Social Sciences (SPSS), versão 14, com base em técnicas estatísticas descritivas.

\section{Resultados}

\section{Aspectos Clínicos}

O tempo de descoberta do diagnóstico apresentou variação ampla: de um ano e dois meses a dezesseis anos, sendo que a maioria das participantes $(n=18)$ havia descoberto sua sorologia em período compreendido entre um 
Sant'Anna, A. C. C. \& Seidl, E. M. F. (2009). Efeitos da Condição Sorológica Sobre as Escolhas Reprodutivas de Mulheres HIV Positivas.

a cinco anos. Quase a metade das mulheres $(n=14)$ referiu que a descoberta de sua sorologia para o HIV ocorreu em conseqüência do adoecimento ou morte do companheiro.
Essas e outras circunstâncias relatadas pelas participantes para a descoberta do diagnóstico estão apresentadas na Tabela 1.

Tabela 1

Circunstâncias da Descoberta da Sorologia Positiva para o HIV, Segundo Relatos das Mulheres Participantes (N=30)

Categorias $\quad f \quad$ Exemplos de relatos

Adoecimento ou morte

do companheiro

Detecção do HIV no pré-natal ou no trabalho de parto

Adoecimento da mulher em decorrência da Aids

Tem cinco anos. Meu esposo que transmitiu pra mim. Ele ficou doente e internou. Ele não sabia que tinha. Ele vinha passando mal até que os médicos pediram um HIV pra ele e deu positivo. Aí, os médicos pediram o meu. Eu não gosto nem de lembrar desse dia. Foi muito triste. (37 anos, vive com parceiro HIV+ há 10 anos, 5 anos de diagnóstico, possui 1 filho HIV-).

"Fizeram meu pré-natal, mas não me disseram nada. Só descobri no hospital, na hora de ter meu filho, um pouco antes de fazer meu parto. Eu não senti nada na hora porque eu nem mesmo acreditei” (18 anos, vive com parceiro HIV- há 5 anos, 1 ano e 9 meses de diagnóstico, possui 1 filho HIV-).

Descobri tem 11 anos. Eu comecei a passar mal, a emagrecer. Quando eu descobri tinha uma filha pequena, ainda de colo. Me levaram pro hospital e fiquei internada por causa de uma tuberculose e da tuberculose descobriram que eu tava com o vírus. Eu não imaginava nunca que pudesse ser essa doença. (42 anos, vive com parceiro há 5 anos, não sabe a sorologia do parceiro, 11 anos de diagnóstico, 2 filhos, um falecido em decorrência do HIV).

Adoecimento

ou morte de filho

Doação de sangue

"Descobri em 2004, quando minha menina morreu. Ela tinha HIV e a gente não sabia . . . depois que vi minha filha morrer eu não me perdôo” (39 anos, sem parceiro, 3 anos de diagnóstico, 1 filho falecido em decorrência do HIV).

"Há um ano e meio que eu sei. Eu fui fazer um exame de sangue pela empresa, numa campanha de prevenção . . Aí, quando eu peguei o exame, deu que eu era positiva" (27 anos, vive com parceiro HIV+ há 8 meses, 1 ano e meio de diagnóstico, sem filhos).

Dentre as participantes, vinte e três faziam uso de medicação anti-retroviral. Quanto à revelação do diagnóstico, vinte e uma mulheres tinham revelado sua condição sorológica para familiares, duas contaram para amigos e sete participantes relataram que não tinham contado para ninguém sobre o seu diagnóstico, exceto para os profissionais de saúde.

Das vinte mulheres que estavam convivendo com parceiro, nove referiram que este era soropositivo para o HIV, outras nove informaram que estes eram soronegativos e duas participantes não souberam informar. Duas mulheres das que estavam com parceiro não haviam revelado ao companheiro sua condição sorológica. O motivo principal explicitado para a não revelação do diagnóstico estaria no medo de rejeição, exemplificado no relato de uma participante:

Ainda não tive coragem de contar, sei que tô sendo errada, mas acho que se ele soubesse não ficaria comigo. De vez em quando ele solta assim, que jamais se envolveria com alguém que tivesse essa doença, então, como é que eu conto? (36 anos, 6 anos de diagnóstico, vive com parceiro HIV- há 3 anos e meio, possui um filho HIV-).

Com relação à condição sorológica dos filhos, das vinte e uma participantes que tinham filhos, quatorze delas de- clararam que estes eram soronegativos para o HIV, quatro referiram filhos soropositivos e três mulheres não haviam testado suas crianças. Um dos principais motivos alegados para a não testagem foi o medo de ter infectado a criança mediante transmissão vertical. O relato abaixo ilustra essa posição:

Não testei eles. Eu não sei se eles têm ou não. Não tenho coragem. Os médicos já me explicaram que seria bom fazer, mas eu não tenho coragem . . . hoje eu sou aidética, e só de pensar que um de meus filhos também pode ser aidético, pode ter essa doença... isso é uma coisa que eu não descanso dia nenhum. (35 anos, 5 anos de diagnóstico, sem parceiro, possui 2 filhos com sorologia desconhecida).

Quanto ao uso de medidas contraceptivas, sete mulheres haviam realizado laqueadura tubária. Devido a este fato, relataram dificuldade em negociar com o parceiro o uso do preservativo nas relações sexuais e referiram uso inconsistente do mesmo. É digno de nota que nove mulheres relataram a abstinência ou redução do número de relações sexuais como medida contraceptiva, o que pode sinalizar a presença de dificuldades na vivência da sexualidade após o diagnóstico de soropositividade. $\mathrm{O}$ uso do preservativo masculino foi mencionado por dezenove mulheres, entretanto, nem sempre de modo consistente. $\mathrm{O}$ uso do preser- 
vativo feminino não foi mencionado por nenhuma participante. Três participantes alegaram que um dos motivos para o uso inconsistente do preservativo estaria no fato de que a camisinha freqüentemente estoura durante o ato sexual, ou que o tamanho do preservativo não se adequaria ao pênis do parceiro, ocasionando queixas do companheiro. $\mathrm{O}$ uso de contraceptivo oral foi citado apenas por uma participante. Muitas mulheres declararam dificuldade em fazer uso do contraceptivo oral por se sentirem sobrecarregadas com o número de medicamentos anti-retrovirais que tomavam diariamente.
Efeitos da Soropositividade sobre as Escolhas Reprodutivas

Do total de trinta participantes, mais da metade $(n=18)$ referiu que a condição de soropositividade modificou o desejo de ter filhos, enquanto que doze mulheres relataram que a descoberta do diagnóstico não modificou esse desejo. Dentre as dezoito participantes que informaram que a condição de soropositividade modificou o desejo de ter filhos, os motivos explicitados estão apresentados na Tabela 2, a partir das categorias identificadas, sua freqüência e exemplos de relatos.

Tabela 2

Motivos Explicitados pelas Participantes que Relataram que a Condição Sorológica Modificou o Desejo de ter Filhos $(n=18)$

\begin{tabular}{|c|c|c|}
\hline Categoria & $f$ & Exemplos de relatos \\
\hline $\begin{array}{l}\text { Receio quanto ao risco } \\
\text { de transmissão do HIV para o filho }\end{array}$ & 9 & $\begin{array}{l}\text {.. Existe um risco de meu filho nascer com o HIV. Será que isso é } \\
\text { amor? Expor seu filho a um risco desses? De ele já nascer com o } \\
\text { vírus? Na minha cabeça ter o vírus modificou sim esta questão. (42 } \\
\text { anos, sem parceiro, } 8 \text { anos de diagnóstico, possui um filho com sorolo- } \\
\text { gia desconhecida para o HIV). ". . a vida toda sonhei em ter um filho, } \\
\text { depois que eu descobri eu não quis mais ter. . . Tenho medo de ele } \\
\text { nascer com o vírus" ( } 27 \text { anos, vive com parceiro HIV+ há } 8 \text { meses, } 1 \\
\text { ano e } 6 \text { meses de diagnóstico, sem filhos). }\end{array}$ \\
\hline $\begin{array}{l}\text { Soropositividade como sinônimo } \\
\text { de morte }\end{array}$ & 4 & $\begin{array}{l}\text { “. . A Acho que quem tem o vírus não pode mais ter filho, eu acho que } \\
\text { devia ser proibido mesmo, porque um dia você vai faltar na vida dessa } \\
\text { criança” ( } 35 \text { anos, sem parceiro, } 5 \text { anos de diagnóstico, possui } 2 \text { filhos } \\
\text { com sorologia desconhecida para o HIV). }\end{array}$ \\
\hline $\begin{array}{l}\text { Experiência de morte do filho } \\
\text { em decorrência do HIV }\end{array}$ & 3 & $\begin{array}{l}\text { “Ah, muda, viu? . . . depois que eu vi o meu filho morrer, eu não me } \\
\text { perdôo . . todo dia eu penso: porque Deus não me levou e deixou meu } \\
\text { menino aqui?” ( } 39 \text { anos, sem parceiro, } 3 \text { anos de diagnóstico, } 1 \text { filho } \\
\text { falecido em decorrência do HIV). }\end{array}$ \\
\hline $\begin{array}{l}\text { Medo de revelar a sorologia para o } \\
\text { parceiro e/ou de expor o parceiro ao HIV }\end{array}$ & 2 & $\begin{array}{l}\text { "É tanta coisa pra se preocupar... primeiro que pra ter um filho eu } \\
\text { ia ter que falar com o meu parceiro, e isso ainda é muito difícil pra } \\
\text { mim" ( } 27 \text { anos, vive com parceiro HIV-há } 2 \text { anos e } 6 \text { meses, } 4 \text { anos de } \\
\text { diagnóstico, sem filhos). }\end{array}$ \\
\hline
\end{tabular}

Dentre as participantes que relataram que a condição de soropositividade não modificou o desejo de ter filhos $(n=12)$, o motivo mais citado foi o fato de que o vírus HIV não

Tabela 3

Motivos Explicitados pelas Participantes que Relataram que a Condição Sorológica Não Modificou o Desejo de ter Filhos $(n=12)$

\begin{tabular}{|c|c|c|}
\hline Categoria & $f$ & Exemplos de relatos \\
\hline $\begin{array}{l}\text { Soropositividade não alterou } \\
\text { projetos de vida }\end{array}$ & 8 & $\begin{array}{l}\text { "Eu tive minha filha sem medo nenhum . . Era o meu sonho ter uma } \\
\text { menina e só realizei depois do vírus ... Não me dei um atestado de óbito } \\
\text { como muita gente faz" ( } 30 \text { anos, vive com parceiro HIV- há } 3 \text { anos, } 11 \\
\text { anos de diagnóstico, possui } 3 \text { filhos HIV-). }\end{array}$ \\
\hline Maternidade comorealização feminina & 3 & $\begin{array}{l}\text { "É lógico que eu queria ter mais filhos. Isso faz parte da mulher" (32 } \\
\text { anos, vive com parceiro HIV- há } 1 \text { ano e } 3 \text { meses, possui } 4 \text { filhos, } 1 \text { HIV+). }\end{array}$ \\
\hline $\begin{array}{l}\text { Dificuldade de se perceber } \\
\text { com uma enfermidade crônica }\end{array}$ & 1 & $\begin{array}{l}\text { "Ainda não caiu a ficha" ( } 23 \text { anos, vive com parceiro HIV+ há } 2 \text { anos, } \\
1 \text { ano e } 2 \text { meses de diagnóstico, sem filhos). }\end{array}$ \\
\hline
\end{tabular}

afetou a vida de modo geral, exemplificado pela formação de novas parcerias conjugais após o diagnóstico e o desejo de constituir novos laços familiares $(n=8)$. Essa e outras categorias identificadas estão na Tabela 3 . 
Sant'Anna, A. C. C. \& Seidl, E. M. F. (2009). Efeitos da Condição Sorológica Sobre as Escolhas Reprodutivas de Mulheres HIV Positivas.

Quando questionadas se tinham vontade de ter filhos, vinte e uma das trinta mulheres responderam negativa- mente. Foram identificadas seis categorias quanto aos motivos para não desejarem ter filhos, conforme descrito na Tabela 4.

Tabela 4 Motivos Relatados pelas Participantes que Não Desejavam Ter Filhos ( $n=21)$

\begin{tabular}{|c|c|c|}
\hline Categoria & $f$ & Exemplos de relatos \\
\hline Condição sorológica & 10 & $\begin{array}{l}\text { ". . eu vejo o HIV quase como uma sujeira, eu não queria expor o meu filho } \\
\text { a isso. Na minha cabeça eu penso que ele pode nascer com algum problema que } \\
\text { a ciência ainda não descobriu” (44 anos, sem parceiro, } 14 \text { anos de diagnóstico, } \\
\text { possui } 5 \text { filhos HIV-). "Acho que essas coisas não são para quem tem HIV, } \\
\text { quem tem HIV tem que cuidar da família, tomar os remédios e se quiser ter um } \\
\text { filho, adota” ( } 35 \text { anos, sem parceiro, } 5 \text { anos de diagnóstico, possui } 2 \text { filhos com } \\
\text { sorologia desconhecida para o HIV). }\end{array}$ \\
\hline $\begin{array}{l}\text { Realização de laqueadura } \\
\text { de trompas }\end{array}$ & 7 & $\begin{array}{l}\text { "Eu não tenho mais vontade e não posso mais ter. Liguei minhas trompas } \\
\text { quando tive meu ultimo filho. A fábrica fechou!" ( } 44 \text { anos, vive com parceiro } \\
\text { HIV+ há } 1 \text { ano, } 5 \text { anos de diagnóstico, possui } 3 \text { filhos HIV-). }\end{array}$ \\
\hline Número de filhos suficiente & 4 & $\begin{array}{l}\text { "Não quero mais porque eu já tenho o que eu queria. Filho homem e filha } \\
\text { mulher. Tô feliz assim” ( } 30 \text { anos, vive com parceiro HIV- há } 3 \text { anos, } 11 \text { anos de } \\
\text { diagnóstico, possui } 3 \text { filhos HIV-). }\end{array}$ \\
\hline $\begin{array}{l}\text { Ausência de projeto } \\
\text { de maternidade }\end{array}$ & 3 & $\begin{array}{l}\text { "Nunca tive essa vontade. Aquela história de instinto materno, acho que isso } \\
\text { não acontece comigo" ( } 29 \text { anos, sem parceiro, } 6 \text { anos de diagnóstico, sem fi- } \\
\text { lhos). }\end{array}$ \\
\hline $\begin{array}{l}\text { Dificuldades financeiras } \\
\text { para a criação de filho }\end{array}$ & 2 & $\begin{array}{l}\text { “. . é difícil criar vários filhos, então pesa a condição financeira” ( } 32 \text { anos, } \\
\text { vive com parceiro HIV- há } 1 \text { ano e } 3 \text { meses, } 4 \text { anos de diagnóstico, possui } 4 \\
\text { filhos, } 1 \mathrm{HIV+)} \text {. }\end{array}$ \\
\hline $\begin{array}{l}\text { Medo de revelar a condição } \\
\text { sorológica ao parceiro }\end{array}$ & 2 & $\begin{array}{l}\text {. . pra um bebê nascer, eu teria que ter relação sexual sem camisinha, e isso } \\
\text { eu acho que não faria sem contar pro meu parceiro. E aí acontece o que? Eu } \\
\text { vou ficar sem filho e sem namorado. ( } 37 \text { anos, vive com parceiro HIV- há } 4 \text { anos, } \\
\text { sem filhos). }\end{array}$ \\
\hline Idade elevada & 1 & $\begin{array}{l}\text { "Eu já to ficando velha” (42 anos, sem parceiro, } 13 \text { anos de diagnóstico, pos- } \\
\text { sui } 1 \text { filho com sorologia desconhecida para o HIV). }\end{array}$ \\
\hline
\end{tabular}

Nota. Algumas participantes relataram mais de um motivo.

Dentre as participantes que relataram o desejo de maternidade $(n=9)$, os principais motivos mencionados foram a vontade do parceiro em ter filhos $(n=4)$ e a crença de que um filho seria um complemento ao relacionamento conjugal $(n=5)$. Entretanto, apesar de relatarem tal desejo, o medo do preconceito e do risco de infectar a criança foram os motivos explicitados para adiarem a realização dos planos de maternidade.

"Eu tenho vontade, só que tenho medo, né? Às vezes o medo é maior que a vontade, sabe? Tenho medo de colocar um bebê doente no mundo" (37 anos, sem parceiro, 9 anos de diagnóstico, sem filhos).

"É difícil dizer que eu não tenho vontade, porque isso faz parte do casamento, né? Que mulher não sonha em casar e ter filhos? . . Ainda falta um pouquinho de coragem" (34 anos, 5 anos de diagnóstico, vive com parceiro HIV+ há 14 anos, sem filhos).

\section{Discussão}

O estudo aponta a relevância da realização de pesquisas na área, contribuindo para o aprimoramento das políticas públicas no âmbito dos direitos reprodutivos de mulheres soropositivas. Embora os resultados não possam ser generalizados para a população feminina brasileira que vive com HIV/Aids, estes indicam vários desafios que merecem atenção.

Mais da metade das participantes fazia uso de terapia anti-retroviral (TARV), dado esperado tendo em vista o acesso gratuito e universal a esses medicamentos desde 1996, no Brasil. Essa política pública tem favorecido a melhoria das condições de saúde e a qualidade de vida das pessoas que vivem com HIV/Aids no país, conforme indicam estudos sobre o tema (Seidl, Zannon, \& Tróccoli, 2005).

Não obstante os avanços no controle da enfermidade e na qualidade de vida, observa-se que a revelação do diagnóstico ainda provoca angústia e apreensão nas pessoas que vivem com HIV/Aids, tanto para aquelas do convívio sócio-familiar quanto para as parcerias sexuais: quase um quarto das participantes não tinha contado para ninguém sobre sua condição sorológica e duas delas não tinham revelado para seus parceiros sexuais estáveis. Quanto à revelação para parcerias sexuais, resultado semelhante foi encontrado por Paiva et al. (2002) ao constatarem que, 
apesar de mais da metade das participantes relatar vida amorosa e sexual ativas, a comunicação do diagnóstico ao parceiro foi citado como um evento estressor.

A revelação do diagnóstico para pessoas de confiança pode ser benéfica pois parece fortalecer a rede de apoio social (Seidl \& Tróccoli, 2006). O medo do preconceito tem sido um dos principais motivos para a manutenção do segredo sobre o diagnóstico (Paiva et al., 2002). Mesmo considerando os benefícios potenciais da revelação do diagnóstico, pela possibilidade de fortalecimento do apoio social, o respeito à decisão sobre revelar ou não a sorologia para terceiros deve ser garantido às pessoas que vivem com HIV/Aids.

Quanto à situação conjugal, pouco mais da metade das entrevistadas estava vivendo com parceiro, muitos deles com sorologia negativa para o HIV. A constituição de casais sorodiferentes demonstra que a melhoria da qualidade de vida das pessoas soropositivas tem favorecido este tipo de parceria que traz, muitas vezes, alguns desafios, tais como informar a condição sorológica ao parceiro e negociar o uso consistente do preservativo nas relações sexuais. Para as mulheres que desejam ter filhos, a sorologia diferente para o HIV suscita questões ainda mais complexas, na medida em que a possibilidade de engravidar pode expor o parceiro ao HIV (Dalapria \& Neto, 2004; Polejack, 2001; Polejack \& Costa, 2002). Nessa questão, é fundamental garantir os avanços previstos na legislação brasileira referentes aos procedimentos de reprodução assistida para os casais, em especial para aqueles com sorologia diferente para o HIV (Ministério da Saúde, 2005).

A maior parte das entrevistadas tinha filhos e, dentre estes, mais da metade eram soronegativos. Como não foi investigado se esses filhos foram concebidos antes ou depois do diagnóstico de soropositividade, os resultados encontrados não permitem concluir sobre os efeitos da profilaxia da transmissão vertical do HIV no número de casos. Dentre as entrevistadas que tinham filhos, três delas não haviam realizado o teste anti-HIV em suas crianças. Esse aspecto chama atenção para uma possível lacuna dos serviços de saúde no que se refere às ações de aconselhamento, que devem explicitar riscos e benefícios da testagem sorológica, em especial para as crianças não avaliadas.

A percepção das participantes quanto aos efeitos da condição de soropositividade sobre as escolhas reprodutivas de mulheres que vivem com HIV/Aids foi o principal objetivo desse estudo. Verificou-se que mais da metade das participantes relataram que a condição sorológica modificou o desejo de maternidade, sugerindo que a soropositividade tem influência importante sobre as escolhas reprodutivas, o que também foi constatado por outros pesquisadores (Barbosa \& Knauth, 2003; Bedimo et al., 1998; Knauth, 1997; Paiva et al., 2002; Santos et al., 2002). O receio de infectar a criança foi o motivo citado por metade das mulheres como justificativa para a modificação do desejo de ter filhos. Verificou-se que essa categoria traduz uma desinformação sobre as possibilidades eficazes de prevenção da transmissão vertical, permeada por concepções fatalistas acerca desse risco. É possível afirmar ainda que, apesar dos avanços no tratamento das pessoas que vivem com HIV/ Aids, a associação entre HIV e morte ainda se faz presente no imaginário de muitas mulheres a ponto de influenciar suas decisões reprodutivas.

Como foi verificado, o desejo de ter filhos sofreu um impacto negativo entre as participantes, visto que cerca de dois terços mencionaram não desejar uma gravidez após o diagnóstico. Dentre as seis categorias encontradas, a condição sorológica foi crucial na extinção deste desejo. Entre as mulheres que manifestaram tal vontade, o medo do preconceito e do risco de contaminar a criança foram os fatores que adiaram os planos de maternidade. Esses achados reforçam o impacto negativo da condição de soropositividade sobre as escolhas reprodutivas, não permitindo que direitos dessa natureza sejam usufruídos.

A vontade de ter ou não filhos tem implicações na adoção de métodos de contracepção. Quase um quarto das participantes havia realizado laqueadura tubária, resultado que vai ao encontro de estudo que apontou a freqüência elevada desse procedimento junto a mulheres brasileiras (Faúndes, Costa, Pádua, \& Perdigão, 1998). Verificou-se ainda que o aconselhamento para o planejamento familiar de mulheres soropositivas parece não ocorrer de modo sistemático nos serviços de saúde investigados. Diante do exposto, é fundamental que os serviços aprimorem e qualifiquem suas ações concernentes ao planejamento familiar de mulheres HIV positivas, ampliando o leque de opções e métodos que poderiam ser disponibilizados. Em paralelo, deve-se discutir o acesso dessas mulheres ao aborto como mais uma opção no campo dos direitos reprodutivos (Barbosa \& Knauth, 2003; Guilhem, 2005).

A abstinência ou redução do número de parceiros, citada por algumas participantes e corroborada por diversos estudos, pode sinalizar dificuldades na vivência da sexualidade após o diagnóstico (Galvão et al., 2004; Paiva et al., 2002). A dificuldade em negociar o uso de preservativo com o parceiro se faz ainda maior nos casos das mulheres submetidas à laqueadura, quando a prevenção da gravidez não pode ser utilizada como motivo para o uso de medidas contraceptivas de barreira, deixando-as numa situação mais vulnerável no que tange às práticas sexuais seguras (Barbosa \& Knauth, 2003; Knauth, Barbosa, Hopinks, Pegoriano, \& Fachini, 2002). O preservativo feminino, importante ferramenta para a autonomia da mulher nessa negociação, parece não estar sendo muito utilizado. Tal aspecto também foi verificado em outras pesquisas e sugere a necessidade de investigações sobre os possíveis determinantes que estão influenciando o comportamento de não-adesão ao preservativo feminino (Galvão et al., 2004).

O relato de algumas participantes sinalizou um uso provavelmente inadequado do preservativo masculino, o que pode indicar a necessidade de uma revisão das práticas educativas em saúde adotadas nos serviços. Entre as lições aprendidas no âmbito da prevenção ao HIV/Aids em mais de duas décadas de epidemia, pode-se mencionar a constatação de que prevenção não se ensina (Ayres, 2002). 
A prática preventiva em saúde evidencia que a comunicação unidirecional, dogmática e autoritária não tem sido eficaz. Além disso, sabe-se que o aprendizado não é fruto da simples aquisição de informação. Para tanto, a realização de oficinas educativas que contemplem nível de escolaridade, aspectos religiosos, crenças e valores morais, origem étnica, podem contribuir para a eficácia das práticas preventivas em HIV/Aids (Ayres, 2001, 2002).

Diante dos resultados obtidos, reafirma-se a necessidade de que os serviços de referência em HIV/Aids atuem em consonância com os programas de atenção à saúde da mulher, de modo integral, calcados nos princípios do Sistema Único de Saúde. Espera-se que este estudo possa contribuir para a melhoria da prática profissional daqueles que trabalham diretamente com pessoas que vivem com HIV/Aids, na medida em que o crescente processo de feminização sinaliza a necessidade de considerarmos o enfoque de gênero nas ações de saúde. Essa discussão certamente suscita questões de análise para pesquisas futuras que contemplem ações de planejamento familiar no contexto da soropositividade e as possíveis influências do acolhimento de tais demandas pelos serviços de saúde.

\section{Referências}

Ayres, J. R. C. M. (2001). Sujeito, intersubjetividade e práticas de saúde. Ciência e Saúde Coletiva, 6(1), 63-72.

Ayres, J. R. C. M. (2002). Práticas educativas e prevenção de HIV/Aids: Lições aprendidas e desafios atuais. Interface Comunicação, Saúde e Educação, 6(11), 11-24.

Barbosa, R. M., \& Knauth, D. R. (2003). Esterilização feminina, Aids e cultura médica: Os casos de São Paulo e Porto Alegre, Brasil. Cadernos de Saúde Pública,19(2), 365-376.

Bardin, L. (1979). Análise de conteúdo. Lisboa, Portugal: Edições 70. (Original publicado em 1977)

Bedimo, A. L., Bessinger, R., \& Kissinger, P. (1998). Reproductive choices among HIV positive women. Social Science and Medicine, 46, 171-179.

Cabral, C. S. (1998). Mujeres VIH positivas y su representación social de la maternidad. In A. Gómez (Ed.), Mujeres, vulnerabilidad y VIH/SIDA. Un enfoque desde los derechos humanos (pp. 98-101). Santiago, Chile: Red de Salud de las Mujeres Latinoamericanas y del Caribe.

Connor, E. M., Sperling, R. S., Gelber, R., Kiselev, P., Scott, G., O'Sullivan, M. J., et al. (1994). Reduction of maternal infant transmission of human immunodeficiency virus type 1 with zidovudine treatment. New England Journal of Medicine, 331, 1173-1180.

Dalapria, T. R., \& Neto, F. R. G. X. (2004). Práticas sexuais e escolhas reprodutivas de casais sorodiferentes para o HIV. Jornal Brasileiro de Doenças Sexualmente Transmissíveis, 16(4), 19-26.

Faúndes, A., Costa, R. G., Pádua, K. S., \& Perdigão, A. M. (1998). Associação entre prevalência de laqueadura tubária e características sociodemográficas de mulheres e seus companheiros no Estado de São Paulo. Cadernos de Saúde Pública, 14, 49-57.

Galvão, M. T. G., Cerqueira, A. T. A. R., \& Marcondes-Machado, J. (2004). Medidas contraceptivas e de proteção da transmissão do HIV por mulheres com HIV/Aids. Revista de Saúde Pública, 38(2), 194-200.
Guilhem, D. (2005). Escravas do risco: Bioética, mulheres e Aids. Brasília, DF: Editora da Universidade de Brasília.

Knauth, D. R. (1997). Maternidade sob o signo da Aids: Um estudo sobre mulheres infectadas. In A. O. Costa (Ed.), Direitos tardios, saúde, sexualidade e reprodução na América Latina (pp. 39-64). São Paulo, SP: Prodir.

Knauth, D. R. (1999). Subjetividade feminina e soropositividade. In R. Barbosa \& R. Parker (Eds.), Sexualidades pelo avesso (pp. 121-136). São Paulo, SP: Ed. 34.

Knauth, D. R., Barbosa, R. M., Hopinks, K., Pegoriano, M., \& Fachini, R. (2002). Cultura médica e decisões reprodutivas entre mulheres infectadas pelo vírus da Aids. Interface - Comunicação, Saúde e Educação, 11, 39-54.

Lopes, F. (2003). Mulheres negras e não-negras vivendo com HIV/Aids no estado de São Paulo: Um estudo sobre suas vulnerabilidades. Tese de Doutorado não-publicada, Universidade de São Paulo, SP.

Ministério da Saúde. (2005). Direitos sexuais e direitos reprodutivos: Uma prioridade do governo. Normas e manuais técnicos. Caderno 1. Brasília, DF: Autor.

Ministério da Saúde. (2006). Recomendações para a profilaxia da transmissão vertical do HIV e terapia anti-retroviral em gestantes. Brasília, DF: Autor.

Ministério da Saúde. (Ed.). (2007). Boletim Epidemiológico Aids e DST, 4(1).

Moreno, C. C. G. S., Rea, M. F., \& Ventura-Filipe, E. (2006). Mães HIV positivo: O dilema da não amamentação. Revista Brasileira de Saúde Materno-infantil, 6(2), 199-208.

Paiva, V., Latorre, M. R., Gravato, N., \& Lacerda, R. (2002). Sexualidade de mulheres vivendo com HIV/Aids em São Paulo. Cadernos de Saúde Pública, 18(6), 1609-1620.

Polejack, L. (2001). Convivendo com a diferença: Dinâmica relacional de casais sorodiscordantes para o HIV. Dissertação de Mestrado não-publicada, Universidade de Brasília, DF.

Polejack, L., \& Costa, L. F. (2002). Aids e conjugalidade: O desafio de com (viver). Impulso, Revista de Ciências Sociais e Humanas, 13, 131-139.

Reis, R. K. (2004). Convivendo com a diferença: O impacto da sorodiscordância na vida afetivo-sexual de portadores do HIVI Aids. Dissertação de Mestrado não-publicada, Universidade de São Paulo, Ribeirão Preto, SP.

Sant'Anna, A. C. C., Seidl, E. M. F., \& Galinkin, A. L. (2008). Mulheres, soropositividade e escolhas reprodutivas. Estudos de Psicologia (Campinas), 25(1), 101-109.

Santos, N. J., Buchalla, C. M., Ventura-Filipe, E., Bugamelli, L., Garcia, S., \& Paiva, V. (2002). Mulheres HIV positivas, reprodução e sexualidade. Revista de Saúde Pública, 36(4), 12-23.

Seidl, E. M. F., \& Tróccoli, B. T. (2006). Desenvolvimento de escala para avaliação do suporte social em HIV/Aids. Psicologia: Teoria e Pesquisa, 22(3), 317-326.

Seidl, E. M. F., Zannon, C. M. L. C., \& Tróccoli, B. T. (2005). Pessoas vivendo com HIV/Aids: Enfrentamento, suporte social e qualidade de vida. Psicologia: Reflexão e Crítica, 18(2), 188-195.

Simões-Barbosa, R. H. S. (2001). Mulheres, reprodução e Aids: As tramas da ideologia na assistência à saúde de gestantes $H I V+$. Tese de Doutorado não-publicada, Fundação Oswaldo Cruz, Escola Nacional de Saúde Pública, Rio de Janeiro, RJ.

Recebido: $17 / 11 / 2007$ $1^{a}$ revisão: $28 / 05 / 2008$ $2^{a}$ revisão: 01/09/2008 Aceite final: 04/09/2008 